\title{
A glomus tumour of the elbow: a case report and review of the literature
}

\author{
Cameron Anley*, Basil Vrettos*, Stephen Roche* \& Michael Solomons ${ }^{\dagger}$ \\ * Department of Shoulder, Groote Schuur Hospital, Cape Town, South Africa \\ tThe Martin Singer Hand Unit, Groote Schuur Hospital, Cape Town, South Africa
}

Received
Received 16 June 2013;
accepted 12 August 2013
Keywords
Glomus, tumour, extradigital, elbow
Conflicts of Interest
None declared
Correspondence
Cameron Anley,
4 Silvester Cottages, Preston-On Stour,
Warwickshire CV37 8NQ, UK.
Tel.: +44 7964882131.
E-mail: cam_anley@yahoo.com
DOl:10.1111/sae.12041

\section{ABSTRACT}

Extradigital glomus tumours are relatively uncommon. We present a case report of a glomus tumour of the elbow and review of the literature with regards to the clinical features, work-up and management of these tumours, to highlight the importance of considering a glomus tumour as part of the differential diagnosis in patient with atypical pain around the elbow.

\section{INTRODUCTION}

A glomus tumour is a rare, soft tissue tumour of the perivascular, temperature-regulating glomus body [1]. Although most commonly considered as a benign tumour, rare cases of malignant tumours have been reported [2,3]. The most common site of presentation of glomus tumours is in the hands, more specifically the digits. Although extradigital tumours are uncommon, a variety of extradigital presentations of a glomus tumour have been described [3-6]. In a study by Takei and Nalebuff, which accumulated the reported cases of extradigital glomus tumours from 1934 to 1992, 19 of 434 (4.4\%) extradigital glomus tumours occurred at the elbow, making this a rare site of this uncommon tumour [4].

Despite a classic triad of signs and symptoms, namely pain, point tenderness and cold sensitivity, it may take several years and visits to a doctor before the diagnosis is established [4-8]. This may be the result of a lack of knowledge of this tumour, especially when presenting in an uncommon site.

We present a case report of a glomus tumour of the elbow and a review of the current literature aiming to highlight the clinical presentation, radiological work-up and management of glomus tumour because these may present with atypical elbow pain but a specific history and should be included in the differential diagnosis.

\section{CASE REPORT}

A 68-year-old male presented with a 6-year history of intermittent pain over the medial aspect of his upper arm, just proximal to the elbow. Although this pain did not affect his daily activities, it was extremely tender to touch. No specific history of cold intolerance was noted. On physical examination, the patient had a full pain-free range of motion of the neck, shoulder, elbow and wrist. Specifically, there were no features in keeping with medial epicondylitis. There was no local tenderness over the medial epicondyle and no pain on resisted wrist flexion. No neurological or vascular fallout was noted in the upper limb. The only positive finding was that of an extremely sensitive and tender point, $2 \mathrm{~cm}$ proximal to the epicondyle. No mass could be palpated.

This patient had previously consulted a shoulder and elbow specialist for the same symptoms in 2008. At that stage, plain radiographs and magnetic resonance imaging (MRI), on a 0.2$T$ scan, were performed and reported as normal. The patient continued with the symptoms, hoping that they would resolve, until consulting a hand surgeon in August 2012, when the above findings were noted. A glomus tumour was suspected as a cause of such exquisite point tenderness. A MRI scan was repeated, which confirmed a $5-\mathrm{mm}$ nodule, $3 \mathrm{~cm}$ proximal to the medial epicondyle. The lesion was hypointense on $\mathrm{T} 1$ and hyperintense on the proton density fat saturation series (Fig. 1). An ultrasound Doppler confirmed the vascular nature of this lesion. The ulnar nerve did not appear to be involved. The diagnosis of glomus tumour was suggested.

Surgery was performed on the patient and a well circumscribed nodule was identified in the subcutaneous fat (Fig. 2). An excision of the nodule was performed and sent for histology, which confirmed a nodule comprising homogenous cells with scanty eosinophilic cytoplasm. The cells had a vague nested growth pattern. The diagnosis of glomus tumour was confirmed, as well as complete excision. 


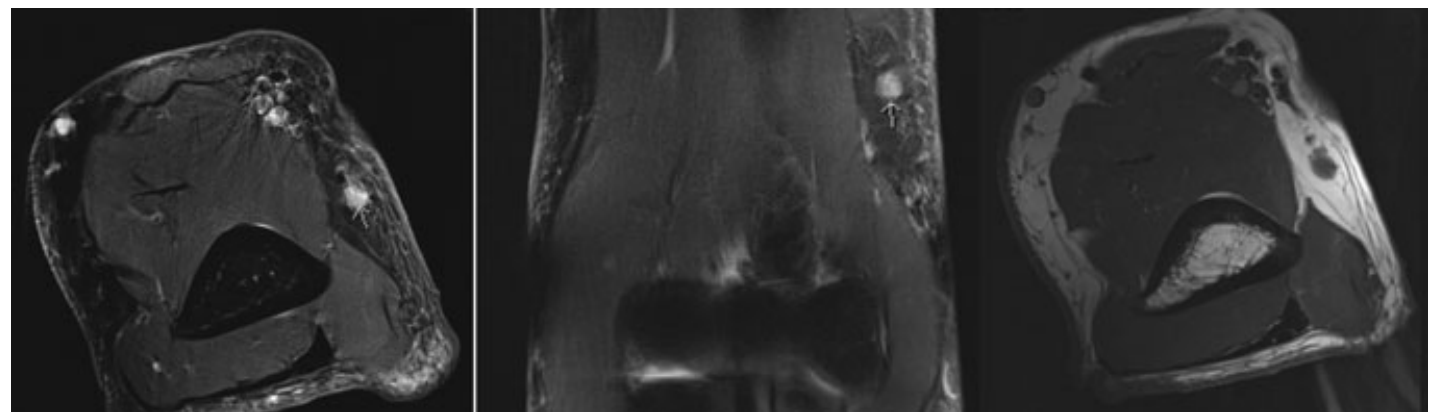

Fig. 1 Magnetic resonance images of the lesion.
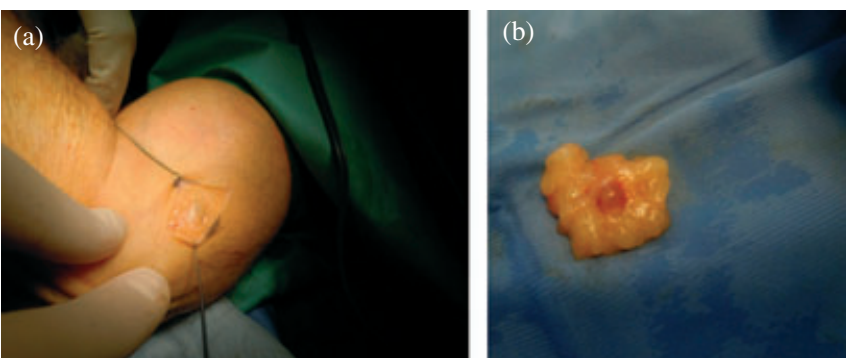

Fig. 2 Intra-operative (a) and biopsy of the lesion showing clear margins (b).

The patient had an uneventful recovery after surgery and, at 3-month follow-up, his symptoms had completely resolved.

\section{DISCUSSION}

The first record of a glomus tumour appears to be the description and management of eight painful subcutaneous tubercles by Wood in $1812[4,8,9]$. Masson, in his article published in 1924, is credited with first using the term glomus tumour to describe a tumour that originated from a contractile neuromyoarterial body, also known as a glomus body [1]. The glomus body has been shown to control blood pressure and temperature via the regulation of peripheral blood flow by functioning as a specialized arteriovenous anastomosis. Typically, these bodies are found in the stratum reticularis layer of the dermis [10] or subcutaneous tissues of the extremities. Glomus tumours are uncommon, with an incidence of $1.5 \%$ to $4.5 \%$ of all benign, soft tissue tumours of the upper extremity [6]. Although most commonly considered a benign tumour, rare cases of malignant tumours have been reported [2,3]. Features suggestive of malignancy include tumours found in a deep location, larger than $2 \mathrm{~cm}$ or those having histological features of malignancy, such as nuclear atypia, necrosis or mitotic activity [2].

The most common site of glomus tumours are the hands and, more specifically, the digits, with a reported incidence of up to $75 \%$ [3-6]. Despite the digits being the classic site of presentation, various cases have been presented of glomus tumuors in extradigital sites. These include the legs, tongue, oesophagus, liver, wrist, neck, hip, genitourinary tract, foot, oral cavity, the triceps tendon, the forearm and elbow $[6,11]$. Takei and Nalebuff reviewed the literature of extradigital glomus tumours, especially those in the upper limb, and found an incidence of $11 \%$ to $65 \%$ [4]. In their review of 434 glomus tumours in the upper limb, $19(4.4 \%)$ occurred at the elbow. In addition, in a review of 20 years of extradigital glomus tumours treated at the Mayo clinic, only four presented at the elbow [6]. The elbow is thus an uncommon site of the relatively rare extradigital glomus tumour.

Digital glomus tumours are more common in females $[4,6,7,11]$, with most patients being aged between 30 years and 60 years at presentation $[4,6]$. By contrast, as with our case, extra digital tumours are four times more common in male patients, where the age of presentation is slightly higher, from 40 years to 70 years $[4,6]$.

The classic clinical presentation of a glomus tumour is a triad of pain, cold intolerance or hypersensitivity and extreme tenderness to touch, and this has been reported to be present in $63 \%$ to $100 \%$ of cases of digital tumours $[7,10]$. In extradigital tumours, pain and point tenderness are the most specific symptoms [6]. With this clinical picture in mind, the diagnosis was made in $90 \%$ of patients based on clinical grounds alone in a study by van Geertruyden [7]. This may, however, be misleading because many studies and case reports have shown, as in our case, that a delay in reaching the diagnosis is common, especially in extra digital presentations. The time to diagnosis is on average of 7 years to 11 years [4-7], ranging from 4 months to 40 years [11]. Most patients attend two to three consultations prior to diagnosis $[6,7,12]$. This highlights the importance of awareness of the symptoms of these tumours. Although commonly described for digital tumours, various clinical tests have been described to aid the diagnosis, including Love's pin test, Hildreth's test and the cold sensitivity test. Bhaskaranand and Navadgi reviewed these tests and concluded that the cold sensitivity test was the most sensitive, specific and accurate [13] but, as previously noted, this is not commonly present in extradigital glomus tumours.

Various imaging modalities have been used in an attempt to improve the rate of diagnosis, including plain film radiography, ultrasound, computed tomography, single-photon emission computed tomography and a MRI scan [3]. Of these, the MRI is suggested as the most reliable for glomus tumours $[3,6]$ with a sensitivity of $90 \%$ and a positive predictive value of $97 \%$ [14]. The specificity, however, is only $50 \%$. The classic findings on MRI include a well-defined lesion with a decreased signal on T1 and with an increased signal on T2. Various studies have advocated surgical exploration in patients with classic signs but a negative 
MRI as a result of some smaller lesion being missed on a MRI $[6,14]$. As noted, with our case, the lesion was originally not seen on a MRI scan performed in 2008. A possible explanation is that this scan was carried out on a 0.2-T scanner and the lesion was on the periphery, which further degrades the image. It is thus likely that this was a false negative as a result of a small lesion and the poor quality of the scan.

The classic clinical picture and findings on MRI should confirm the diagnosis. However, as always, a differential diagnosis should be considered. Various conditions may present in a similar manner including benign or malignant soft tissue masses. The differential diagnosis for soft tissue solid masses is extensive and includes benign tumours, nerve sheath tumours, vascular tumours (e.g. venous malformations, haemangiomas, arteriovenous malformations), leiomyoma and dermatofibroma. An important and sometimes difficult differentiation is the malignant soft tissue sarcomas, such as a synovial sarcoma, leiomyosarcoma, malignant fibrous histiocytoma (for the deep lesions particularly), dermatofibrosarcomaprotuberans and metastases [3].

The preferred treatment of glomus tumours remains surgical exploration and complete excision of the tumour. Care should be taken to ensure that the lesion is completely resected to prevent recurrence. A recurrence rate of $12 \%$ to $33 \%$ is reported in the literature $[6,12]$. Recurrence as a result of inadequate excision normally presents within weeks of surgery, whereas recurrence presenting years later is more likely to be a new process or multiple tumours [6,12]. Although specific techniques have been described for the excision of digital tumours [10], the surgical approach used for extradigital tumours is dependent on the site of the tumour. The use of pre-operative MRI can assist with both the diagnosis and the pre-operative planning with regard to neighbouring vital structures. Surgery is normally very successful and, as with the present case, complete surgical excision results in immediate relief of the symptoms $[3,10,11]$.

\section{CONCLUSIONS}

We present a case of a relatively rare tumour presenting in an uncommon site to highlight the importance of considering a glomus tumour as part of the differential diagnosis in a patient with atypical pain around the elbow. Knowledge of the relatively typical history and MRI findings will hopefully decrease the time to diagnosis and allow for early curative surgical treatment. When suspecting a glomus tumour as a cause of pain around the elbow, a modern high resolution (1.5- or 3-T) scanner should be used. A bead marking the painful area is also recommended. A thorough history and examination and discussion with the radiologist remain essential. It is important to pay attention to detail to ensure a complete excision of the lesion and thus decrease the recurrence rate.

\section{References}

1. Riddell D, Martin R. Glomus tumor of unusual size. Clin Orthop Relat Res 1951; 133:401-3.

2. Folpe AL, Fanburg-Smith JC, Miettinen M, Weiss SW. Atypical and malignant glomus tumors: analysis of 52 cases, with a proposal for the reclassification of glomus tumors. Am J Surg Pathol 2001; 25: $1-12$.

3. Glazebrook K, Laundre B, Schiefer T, Inwards C. Imaging features of glomus tumors. Skeletal Radiol 2011; 40:855-62.

4. Takei TR, Nalebuff EA. Extradigital glomus tumour. J Hand Surg [Br] 1995; 20:409-12.

5. Carroll RE, Berman AT. Glomus tumors of the hand: review of the literature and report on twenty-eight cases. J Bone Joint Surg 1972; 54A:691-703.

6. Schiefer TK, Parker WL, Anakwenze OA, Amadio PC, Inwards CY, Spinner RJ. Extradigital glomus tumors: a 20-year experience. Mayo Clin Proc 2006; 81:1337-44.

7. Van Geertruyden J, Lorea P, Goldschmidt D, et al. Glomus tumors of the hand. A retrospective study of 51 cases. J Hand Surg 1996; 21B:257-60.

8. Varian J, Cleak D. Glomus tumours in the hand. Hand 1980; 12:293-9.

9. Wood W. On painful subcutaneous tubercle. Edinb Med J 1812; 8:283-84.

10. McDermott E, Weiss A. Glomus tumors. J Hand Surg 2006; 31A:1397-1400.

11. Heiney J, Leeson M. Unique size and location of a glomus tumor with a review of the literature. J Shoulder Elbow Surg 2009; 18:e1-3.

12. Fazwi R, Chandran P, Ahmad T. Glomus tumour: a retrospective review of 15 years experience in a single institution. Malays Orthop J $2011 ; 5: 8-12$.

13. Bhaskaranand K, Navadgi BC. Glomus tumour of the hand. J Hand Surg 2002; 27B:229-31.

14. Al-Qattan MM, Al-Namla A, Al-Thunayan A, Al-Subhi F, El-Shayeb AF. Magnetic resonance imaging in the diagnosis of glomus tumours of the hand. J Hand Surg Br 2005; 30:535-40. 